\title{
EARLY SURGICAL REPAIR OF PENILE FRACTURES
}

\author{
J. E. MENSAH ${ }^{1}$, B. MORTON ${ }^{2}$ and M. KYEI ${ }^{2}$ \\ ${ }^{1}$ University of Ghana Medical School, Department of Surgery, PO Box 4236, Accra, Ghana ${ }^{2}$ Korle Bu \\ Teaching Hospital, Department of Surgery, P.O. Box 77, Korle Bu, Accra, Ghana
}

Corresponding Author: Dr James E. Mensah

Email: jemensah@hotmail.com

Conflict of Interest: None declared

\section{SUMMARY}

Objectives: To present our experience with diagnosis and surgical management of penile fracture Patients and methods: We present six cases of penile fracture managed at our unit between 2003 and 2008. The diagnosis was based on clinical presentation and physical examination. The treatment was surgical in all cases with Subcoronal circumferential degloving incision, evacuation of hematoma and reconstruction of the rupture with absorbable suture.

Results: The clinical diagnosis of penile fracture was accurate in all six cases. All patients had a successful outcome, with preservation of erectile function Conclusion: Penile fracture is a clinical diagnosis and immediate surgical repair offers complete recovery of sexual function

Keywords: penile fracture, truama, rupture, diagnosis, treatment

\section{INTRODUCTION}

Penile fracture is a relatively uncommon condition that is defined as the rupture of the corpus carvernosum and or the corpus spongiosum caused by blunt trauma to the erect penis. This excludes penetrating and degloving injuries or amputation of the flaccid penis. The true incidence is not known but is perhaps much higher than reported because many patients do not seek medical attention due to embarrassment or fear. ${ }^{1,2}$

Vaginal intercourse is the most common known cause of penile fractures, with frequencies of $33-58 \%$ of all injuries. $^{2}$ In Middle Eastern countries, a large percentage is due to forceful bending of the erect penis to achieve detumescence, a practice known as 'Taghaandan'. ${ }^{3}$ Because of the rarity of this condition, the optimal diagnostic approach and management is still controversial.

The diagnosis of penile fracture is based on the patient's history and clinical findings. At the time of the fracture, the patient (and sometimes the sexual partner) typically hears a loud cracking noise associated with loss of erection, penile pain and swelling. The above presentation is considered by many to be diagnostic. Others believe that there is a need for preoperative evaluation with carvernosography, retrograde urethrography or MRI. Earlier reports on the management of this injury advocated conservative management with cold compresses and a variety of anti-inflammatory and fibrinolytic therapies. ${ }^{4}$ Currently immediate surgical repair is the treatment of choice. We present our experience with penile fracture diagnosed solely on clinical findings and managed with immediate surgical repair.

\section{PATIENTS AND METHODS}

This study consists of 6 consecutive patients who were admitted to the urology unit of korle bu teaching hospital between December 2003 and January 2008 with a diagnosis of penile fracture. All the patients gave a clear history of sustaining blunt trauma to the erect penis, hearing a cracking or popping sound, followed by rapid detumescence, sharp penile pain and swelling (Figure 1).

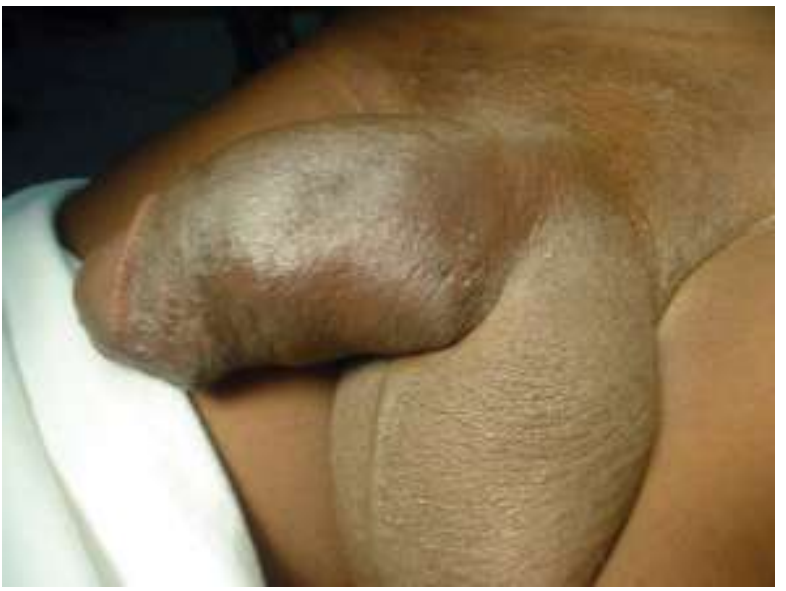

Figure 1 Typical penile deformity in a patient with penile fracture

Assessment of the patients included a full history and a careful clinical examination with emphasis on the cause of the fracture, interval since injury, extent of penile hematoma, signs of blood at the external meatus and side of penile curvature. 
The diagnosis was made clinically in all cases and this included penile swelling and deformity. Most patients had significant tenderness on palpation of the penile shaft. None of the patients had heamaturia or voiding difficulties. No radiographic studies were done to confirm the diagnosis

All the patients underwent surgery on the day of presentation. The penis was explored through a circular subcoronal incision (Figure 2).

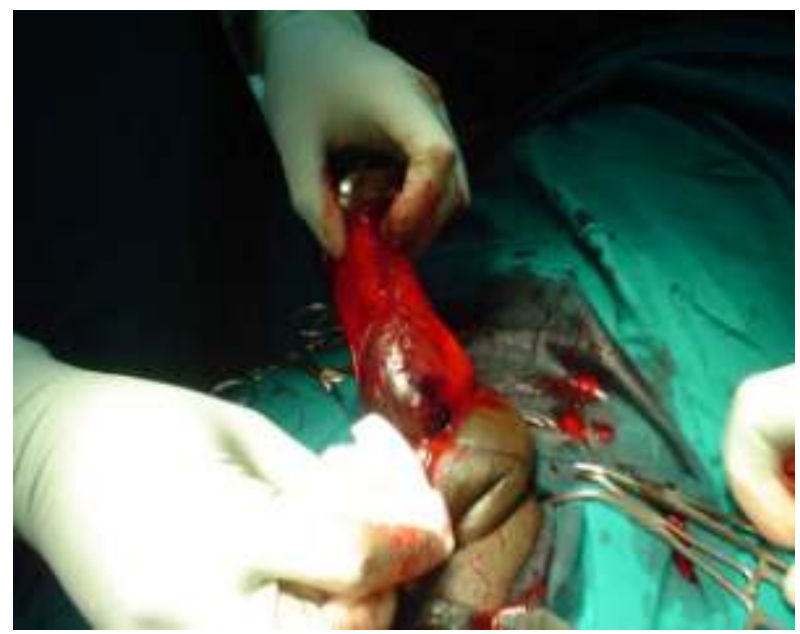

Figure 2 Penis degloved to expose fracture site

The penis was degloved to allow a thorough inspection of all three corporeal bodies. A haematoma beneath the Buck's fascia was seen in five cases .In one case the injury breached the Buck's fascia resulting in the extension of the haematoma into the scrotum. After application of a tourniquet proximal to the fracture site, the haematoma was evacuated and the tear identified (Figure 3).

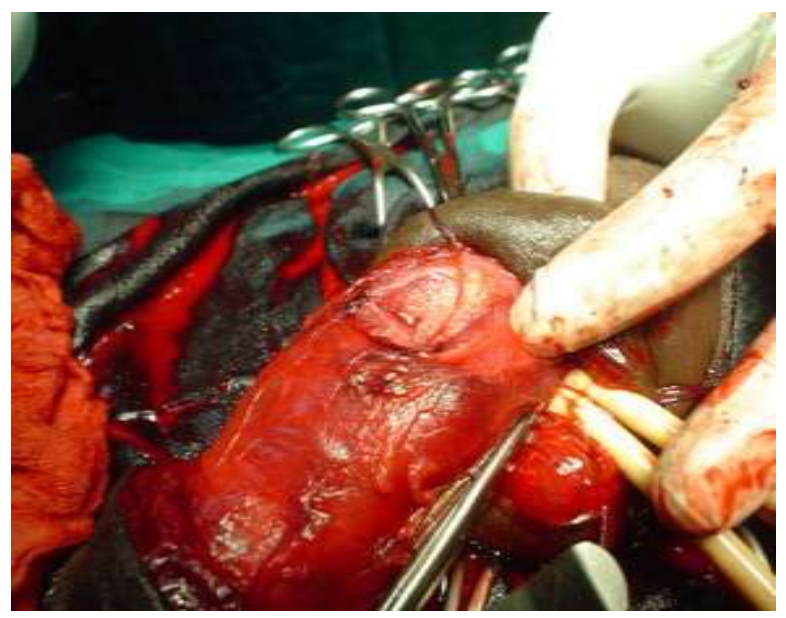

Figure 3 Exposed tear in the tunica albuginea
The tear in the tunica albuginea was then closed with 3.0 interrupted vicryl sutures (Figure 4).

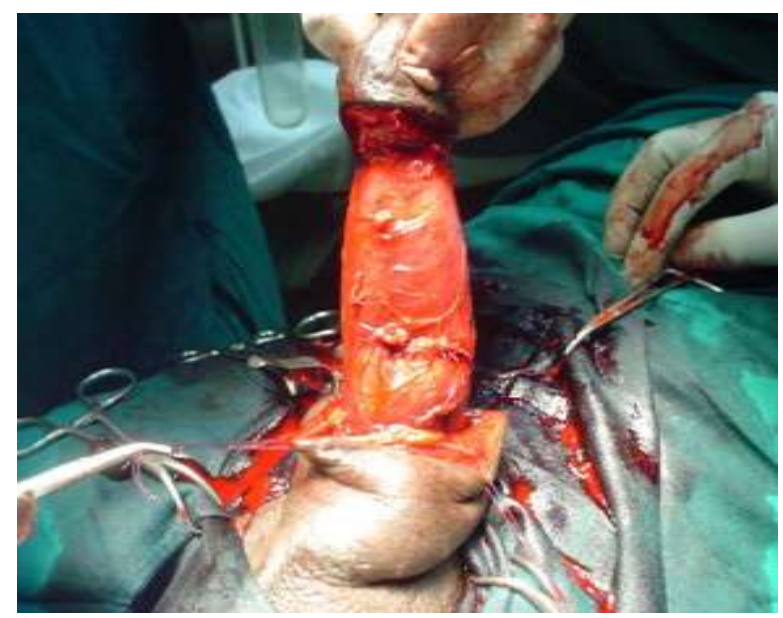

Figure 4Tunica albuginea tear sutured

All patients received prophylactic antibiotics in the form of IV cefuroxime $1.5 \mathrm{gm}$ start. A Foley catheter was inserted in all cases and removed on the second postoperative day. Patients were discharged on tablet ciprofloxacin $500 \mathrm{mg}$ twice daily for seven days and advised to abstain from sexual intercourse for six weeks. The patients have been followed up with emphasis on erection and voiding

\section{RESULTS}

The interval between injury and presentation ranged between 4 and 72 hours. The injury was sustained during vaginal intercourse in three patients. Two of these three patients were having intercourse in the missionary position and one 'the woman on top' position. One patient sustained the fracture when he rolled over the erect penis in bed (to pick a mobile phone).

Two patients claimed to have sustained the fracture while trying to tuck their erect penises into their pants. One later admitted to being under the influence of marijuana when the incident occurred. The clinical diagnosis was confirmed at surgery in all cases The site of the fracture was in the distal third of the penis in 5 patients and at the penoscrotal junction in one patient All the tears in the tunica albuginea were unilateral and transverse with no urethral involvement

There were no significant post operative problems and the average hospital stay was four days (range 3-6). The mean follow up was 20 months (range 7 to 40). 
All the patients reported normal erection and sexual activity except one patient who at the last follow up visit has not attempted sexual intercourse due to the fear of re-fracture.

\section{DISCUSSION}

During erection the engorgement of the corporeal bodies with blood thins out the surrounding tunica albuginea from $2 \mathrm{~mm}$ to $0.5-0.25 \mathrm{~mm}^{2}$

This reduction in thickness and associated loss of mobility make the tunica albuginea of the erect penis vulnerable to fracture. The fracture is usually followed by haematoma at the site of fracture that can spread to the scrotum, perineum and suprapubic area when Buck's fascia is disrupted.

The mechanism of injury is usually a direct blunt force causing a sudden bending of the erect penis .This most commonly occurs during vaginal intercourse either in the 'woman on top position' when her entire weight lands on the erect penis or in the 'missionary position' when the penis misses the introitus and is thrust against the symphysis pubis or perineum.

A variety of other causes of penile fracture have been reported, including bending during masturbation or after a sudden deliberate penile kneading and snapping to achieve detumescence, or unconscious nocturnal manipulation. ${ }^{5,6}$ Other bizarre causes include rolling out of bed and striking a wall, hitting a toilet seat, being thrown against the knob of a saddle, rolling out of a chair onto the floor. $1,2,7$

The diagnosis of penile fracture was predicted from the history and physical examination in all our patients. Some investigators have recommended the use of ultrasound, carvernosography and magnetic resonance imaging to locate the site of the tunical tear before surgery. ${ }^{8,9,10}$ However, the positive predictive values in these studies have been shown to be similar to that of history and clinical examination. ${ }^{11,12}$

The operative findings in this series confirmed the clinical diagnosis in all cases, including the location of the tear. History and physical examination are, therefore, reliable enough to make a firm diagnosis and the added expense of these additional tests should be avoided.

The only important imaging study is a retrograde urethrogram, which should be selectively performed to identify a concomitant urethral tear that occurs in approximately in $10-22 \%$ of reported cases ${ }^{6.7}$, such patients present with blood at the urethral meatus, haematuria or urinary retention. ${ }^{13}$
None of the patients presented with these aforementioned signs proceeded to surgery without any imaging tests. At surgery, there was no evidence of urethral wall disruption or trauma in all six patients.

The management of penile fracture has previously been controversial because early reports favoured a nonoperative approach. This included application of cold compresses, anti-inflammatory agents, instructions to abstain from sexual intercourse, and suppression of erections with antiandrogens. ${ }^{4,14}$ However, current literature tends to support immediate surgical repair. In a recent report the success rate was $92 \%$ for immediate surgical repair and $59 \%$ for conservative management. 15 The complication rate for conservative management was reported to be about $30 \%$, this included fibrous tissue formation with deviation of the penis during erection, prolonged hospital stay and impotence $15,16,17$ compared with less than $10 \%$ for immediate surgical repair. $^{18}$

All the patients in this series underwent immediate surgical repair to avoid the potential complications of conservative management. Several incisions to approach the fracture site have been described including a circumcising degloving incision, midline peno-scrotal, inguino-scrotal, and lateral incision. .,15,16 $^{-1,}$ A degloving circumcising incision was used in all the cases because it allows excellent exposure of the whole penis and penile urethra.

In conclusion, penile fracture is a urological emergency. Immediate surgical exploration and repair offers the best chance of healing with preservation of erectile function. The patient's history and clinical examination is usually enough to make the diagnosis and imaging studies should be performed only in cases of suspected urethral injury.

\section{REFERENCE}

1. Orvis, B. R. and McAninch, J. W. Penile rupture. Urol Clin North Am1989;16:369-375

2 Eke N. Fracture of the penis. Br J Surg 2002; 89: 555-65

3. Zargooshi J. Penile fracture in Kermanshah, Iran: the long-term results of surgical treatment $\mathrm{Br} J$ Urol Int 2002; 89: 890-4

4. Kalash, S. S. and Young, J. D., Jr.: Fracture of penis: controversy of surgical versus conservative treatment Urology 1984; 24: 21-5

5. Van Der Horst C, Martinez Portillo FJ, Seif C, Groth W, Junemann KP. Male genital injury. $\mathrm{Br}$ J Urol Int 2004;93:927-30

6. Fergany AF, Angermeier KW, Montague DK. Review of Cleveland Clinic experience with penile fracture Urology 1999; 54: 352-5 
7. Kowalczyk J, Athens A, Grimali A. Penile fracture: an unusual presentation with lacerations of bilateral corpora cavernosa and partial disruption of the urethra Urology 1994; 44: 599601

8. Koga S, Saito Y, Arakaki N, et al: Sonography in fracture of the penis $\mathrm{Br} J$ Urol 1993;72: 228229,

9. Pruthi RS, Petrus CD, Nidess R, Venable DD. Penile fracture of the proximal corporeal body. $J$ Urol 2000;164: 447-8

10. Ahmad Abolyosr, Alaa E. Abdel Moneim, Atef M. A, et al. The management of penile fracture based on clinical and magnetic resonance imaging findings Br J Urol 2005; 72: 373-377

11. Asgari MA, Hosseini SY, Safarinejad MR, et al: Penile fractures: evaluation, therapeutic approaches and long-term results J Urol 1996; 155: 148-149,

12. Mydlo JH, Hayyeri M, and Macchia RJ: Urethrography and carvernosography imaging in a small series of penile fractures: a comparison with surgical findings Urology 1998; 51: 616619, 1998

13. Mydlo JH. Surgeon experience with penile fracture .J Urol 2001;166: 528-9

14. Muentener M, Suter S, Hauri D, Sulser T.Longterm experience with surgical and conservative treatment of penile fracture. J Urol 2004;172: 576-9

15. Cummings, J. M., Parra, R. O. and Boullier, J. A.: Delayed repair of penile fracture. J Trauma 1998; 45: 153,

16. Penson DF, Seftel AD, Krane RJ, Frohrib D, Goldstein I. The hemodynamic pathophysiology of impotence following blunt trauma to the erect penis J Urol 1992; 148: 1171-80

17. Uygur MC, Gulerkaya B, Altug U, Germiyanoglou C, Erol D.13 years' experience of penile fracture. Scand J Urol Nephrol 1997;31: 265-6

18. Wespes E, Simon L, and Schulman C: Fracture of the penis: conservative versus surgical treatment. Eur Urol 1987;13:166-168 